\title{
QUALIDADE DA ÁGUA DO RIO RIBEIRA DE IGUAPE DA ÁREA DE EXTRAÇÃO DE AREIA NO MUNICÍPIO DE REGISTRO, SP
}

\author{
Ribeira de Iguape River water quality at a sand ex traction \\ area in the municipality of Registro, SP
}

\section{Antônio Fernando Genvásio Leonando ${ }^{\mathrm{a}}$, Leonardo Tachibana ${ }^{\mathrm{b}}$, Camila Fernandes Corrêac, Milena Ribeiro Kokid ${ }^{d}$, Antonio Lobo N eto ${ }^{\mathrm{e}}$, Ana E liza Baccarin ${ }^{\mathrm{f}}$}

a Biólogo, D outor em Aquicultura, Pesquisador Científico, Polo Regional do Vale do Ribeira, Registro, SP - Brasil, e-mail: afleonardo@apta.sp.gov.br

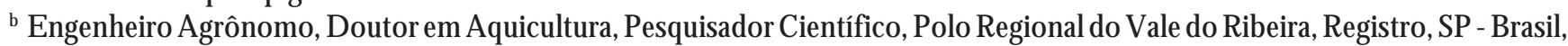
e-mail:leotachibana@ apta.sp.gov.br

c Zootecnista, Mestre em A quicultura, Pesquisadora Científica, Polo Regional do Vale do Ribeira, Registro, SP - Brasil, e-mail: cfcorrea@apta.sp.gov.br

d Estudante de A gronomia, Universidade E stadual Paulista Julio de Mesquita Filho Unidade D iferenciada de Registro, Registro, SP - Brasil, e-mail: milenakoki@ hotmail.com

e Estudante de A gronomia, Universidade E stadual Paulista Julio de Mesquita Filho Unidade D iferenciada de Registro, Registro, SP - Brasil, e-mail: ohlobo1@ hotmail.com

f Zootecnista, D outora em Aquicultura, Fundação Instituto de Terras do Estado de São Paulo, Registro, SP - Brasil, e-mail: anaeliza@itesp.sp.gov.br

\section{Resumo}

As ações antrópicas nas margens e no leito dos rios podem gerar sérios problemas se não praticadas de forma ambientalmente, socialmente e economicamente responsável. E ste estudo teve como objetivo avaliar o efeito da extração de areia sobre a qualidade físico-química da água do Rio Ribeira de Iguape no trecho onde essa atividade foi desenvolvida. D urante os meses de janeiro a dezembro de 2007 os parâmetros limnológicos foram aferidos mensalmente em cinco pontos de coleta, sendo 0 primeiro ponto fora da área de extração de areia (FA) localizado na junção do Rio Ribeira de Iguape com o rio Juquiá e os outros quatro pontos localizados na Área de Extração de Areia (EA). Os parâmetros aferidos foram: oxigênio dissolvido $\left(\mathrm{O}_{2} \mathrm{D}\right), \mathrm{pH}$, transparência $(\mathrm{cm})$, temperatura $\left({ }^{\circ} \mathrm{C}\right)$, alcalinidade total ( $\left.\mathrm{mg} \mathrm{CaCO}_{3} \mathrm{~L}^{-1}\right)$, amônia total $\left(\mathrm{mg} \mathrm{L}^{-1}\right)$, condutividade elétrica ( $\left.\mathrm{mm} \mathrm{L}^{-1}\right)$. Nos cinco pontos de coleta os valores médios observados durante os doze meses foram: oxigênio dissolvido ( $\left.\mathrm{mg} \mathrm{O}_{2} \mathrm{D} \mathrm{L}^{-1}\right): 7,49 \pm 0,2 ; \mathrm{pH}: 7,28 \pm 1,0$; transparência $(\mathrm{cm}): 60,64 \pm 6,47$; temperatura $\left({ }^{\circ} \mathrm{C}\right): 23,23$ $\pm 0,22^{2}$, alcalinidade total $\left(\mathrm{mgCaCO}_{3} \mathrm{~L}^{-1}\right): 74,15 \pm 6,10$; amônia total $\left(\mathrm{mg} \mathrm{L}^{-1}\right): 0,012 \pm 0,006$; condutividade elétrica $\left(\mathrm{mm} \mathrm{L}^{-1}\right) 71,69 \pm 8,34$. A alteração em alguns parâmetros já era de se esperar, 
como a temperatura e transparência da água devido às condições climáticas (verão a verão, chuvas e estiagem). O s valores da condutividade elétrica e alcalinidade total, que estão relacionados com íons dissolvidos no ambiente, apresentaram-se mais elevados no ponto (FA) $107,63 \pm 22,9 \mathrm{~mm} \mathrm{~L}^{-1} \mathrm{e}$ $105,71 \pm 23,8 \mathrm{mgCaCO}_{3} \mathrm{~L}^{-1}$, quando comparado aos pontos de extração de areia (EA), 62,71 \pm $4,45 \mathrm{~mm} \mathrm{~L}^{-1}$ e $68,50 \pm 2,83 \mathrm{mgCaCO}_{3} \mathrm{~L}^{-1}$, respectivamente. Uma vez que 0 ponto (FA) se encontrava na junção dos rios Ribeira de Iguape e Juquiá, a mistura das águas proporcionou um acúmulo de íons dispersos no ambiente, agindo diretamente no aumento desses parâmetros. E mbora diferenças tenham sido encontradas para os parâmetros limnológicos analisados, os valores médios observados se encontram dentro dos limites adequados para o desenvolvimento da ictiofauna. D essa forma, a atividade de extração de areia não alterou a qualidade da água do Rio Ribeira de Iguape.

Palavras-chave: Registro; Extração de areia; Parâmetros limnológicos.

\begin{abstract}
Man action on river side and on river bed may generate damages if not practiced with environmental, social and economical responsibility. This study aimed to evaluate the effect of sand extraction on physical chemical quality of Ribeira de Iguape River water, at the portion in Registro town, where this activity is developed. From January to December of 2007 year, limnology parameters were measured monthly in five collecting points. First point was out of sand extraction area (FA), in Ribeira de Iguape River and Juquia River junction. The other four points where next of sand extraction areas (EA). Measured parameters were: dissolved oxygen $\left(\mathrm{O}_{2} \mathrm{D}\right), \mathrm{pH}$, water transparency $(\mathrm{cm})$, temperature $\left({ }^{\circ} \mathrm{C}\right)$, total alkalinity $\left(m g \mathrm{CaCO}_{3} \mathrm{~L}^{-1}\right)$, total ammonia $\left(\mathrm{mg} \mathrm{L}^{-1}\right)$ and electric conductivity $\left(m m L^{-1}\right)$. During twelve months, at the five points of water collection, average values observed were: dissolved oxygen $\left(m g \mathrm{O}_{2} D \mathrm{~L}^{-1}\right): 7.49 \pm 0.2 ; \mathrm{pH}: 7.28 \pm 1.0$; transparency $(\mathrm{cm}): 60.64 \pm 6.47$; temperature $\left({ }^{\circ} \mathrm{C}\right): 23.23 \pm 0.22$; total alkalinity $\left(\mathrm{mgCaCO}_{3} \mathrm{~L}^{-1}\right): 74.15 \pm 6.10$; total ammonia $\left(\mathrm{mg} \mathrm{L}^{-}\right.$ 1): $0.012 \pm 0.006$; electric conductivity $\left(\mathrm{mm} \mathrm{L}^{-1}\right) 71.69 \pm 8.34$. Some alterations in parameters like temperature and transparency were expected because of weather conditions (summer to winter, rainy and dry weather). Electric conductivity and total alkalinity values are related to environment dissolved ions that were higher in FA point $\left(107.63 \pm 22.9 \mathrm{~mm} \mathrm{~L}^{-1}\right.$ and $\left.105.71 \pm 23.8 \mathrm{mgCaCO}_{3} \mathrm{~L}^{-1}\right)$ when compared with sand extraction areas (EA) $\left(62.71 \pm 4.45 \mathrm{~mm} \mathrm{~L}^{-1}\right.$ and $\left.68.50 \pm 2.83 \mathrm{mgCaCO} \mathrm{L}^{-1}\right)$. FA point was in two river junction and water mixing caused environment dispersed ions accumulation, acting directly in these parameters increase. Though differences in analyzed limnology parameters were found, observed average values were in adequate limits for fish development. Concluding sand extraction activity did not altered water quality of Ribeira de Iguape River.
\end{abstract}

Keywords: Register; Sand extraction; Limnology parameters.

\title{
INTRODUÇÃO
}

As bacias hidrográficas no Brasil estão perdendo sua configuração original devido à construção de reservatórios para usinas hidrelétricas. Além disso, as ações antrópicas à beira dos rios e os esgotos domésticos das grandes cidades estão degradando cada vez mais os ambientes aquáticos continentais.

Segundo Barrella, Beaumord e Petrere (1994) a ação do homem tem provocado uma série de perturbações no funcionamento desses ecossistemas. Historicamente, o manejo das bacias hidrográficas nunca apresentou uma preocupação com a conservação dos recursos naturais renováveis para uma exploração sustentável. A ideia era de que os recursos abundantes eram considerados como inesgotáveis e, por isto, o ambiente poderia ser explorado livremente sem nenhuma restrição (IUCN, 1984). 
A bacia do Rio Ribeira de Iguape ainda não compartilha do parágrafo acima citado. Nessa bacia o maior problema é que em alguns trechos, ou quase todo, o que ocorre é a ausência de mata ciliar contornando o leito do rio. Segundo Branco e Rocha (1977), os cursos de águas de cabeceiras são riachos pequenos e frágeis, onde a cobertura vegetal das margens é de extrema importância, pois evita a erosão dos solos adjacentes, impedindo a sedimentação ou assoreamento do leito do rio.

O assoreamento resulta na perda dos hábitats aquáticos, já que o rio torna-se cada vez mais raso, estreito e canalizado. As espécies que vivem no rio não mais encontram as condições adequadas de alimentação e reprodução, contribuindo, assim, para o declínio da biodiversidade do sistema (BERKMAN; RABENI, 1987). O utros efeitos do assoreamento são o rebaixamento do lençol freático e a diminuição da quantidade de água que brota em seus mananciais, trazendo como consequência a diminuição na vazão, principalmente nas porções superiores das bacias hidrográficas segundo Barrella et al. (2001).

Segundo o Sumário Mineral/ 2001, publicado pelo D NPM (2002), a mineração da areia em leitos de rios é responsável por $90 \%$ da produção brasileira. No Estado de São Paulo, a relação é de: $45,0 \%$ proveniente de várzea, 35,0\% de leitos de rios e o restante de outras fontes. Segundo Lelles et al. (2005) o empreendimento, denominado extração de areia em cursos d'água, apresenta forte perfil impactante e, portanto, faz-se necessário à compreensão, em base científica, dos reais impactos, o que justifica a avaliação prévia da compatibilidade do seu desenvolvimento, com a conservação dos recursos naturais.

Com base nessas informações, o presente trabalho teve como objetivo avaliar o efeito da extração de areia sobre a qualidade físico-química da água do Rio Ribeira de Iguape no trecho onde essa atividade foi desenvolvida, durante os doze meses de 2007 no município de Registro, SP.

\section{MATERIAL E MÉTODOS}

D urante os meses de janeiro a dezembro de 2007 foram coletadas mensalmente amostras de água em cinco pontos no Rio Ribeira de Iguape, sendo quatro deles na área de extração de areia nos devidos portos Pirâmide, Seguro, Boa Vista, G uaviruva e o quinto ponto foi fora da área de extração de areia (Junção do Rio Juquiá e Ribeira); os parâmetros limnológicos analisados foram:

- Oxigênio dissolvido ( $\mathrm{mg} /$ litro) e temperatura da água $(\stackrel{\circ}{-})$ amostrados por meio de oxímetro digital YSI 55;

- Potencial hidrogeniônico $(\mathrm{pH})$ amostrado por um pH-metro digital YSI 64;

- Transparência da água avaliada através do disco de SECCHI (cm);

- Amônia total analisada (mg/litro), segundo metodologia de Koroleff (1976);

- Condutividade elétrica amostrada por um condutivímetro digital $(\mathrm{mm} / \mathrm{litro})$;

- Alcalinidade total foi analisada por titulometria $\left(\mathrm{mgCaC}_{03} /\right.$ litro), segundo metodologia de Golterman et al. (1978).

\section{RESULTADOS E DISCUSSÃO}

Os resultados nos cinco pontos de coleta estão apresentados nas Figuras de 1 a 7 e quando observadas pode-se constatar que os parâmetros de qualidade da água se alteram durante os meses nos cinco pontos de coleta.

Para os valores de oxigênio dissolvido (Figura 1) durante os meses de janeiro a abril foram observados valores médios de 6,6 \pm 0,3 $\mathrm{mg} / \mathrm{L}$ que podem ser considerados dentro dos padrões para 0 desenvolvimento da ictiofauna e os demais organismos do ecossistema aquático (ARANA, 1997). 0 aumento do teor de oxigênio no rio foi gradualmente se elevando nos meses mais frios (maio a agosto) onde os valores médios foram de 8,4 $\pm 0,5 \mathrm{mg} / \mathrm{L}$. Essa elevação é compreensível, pois águas mais frias possuem maior capacidade de dissolução de oxigênio. Além disso, exceto para o mês de julho, cujo 
índice pluviométrico foi mais elevado (Figura 8), no período de maio a setembro os índices de chuva foram muito baixos, o que proporcionou a formação de pequenas corredeiras ao longo do rio, aumentando a velocidade da água agindo diretamente no aumento do teor de oxigênio no rio.

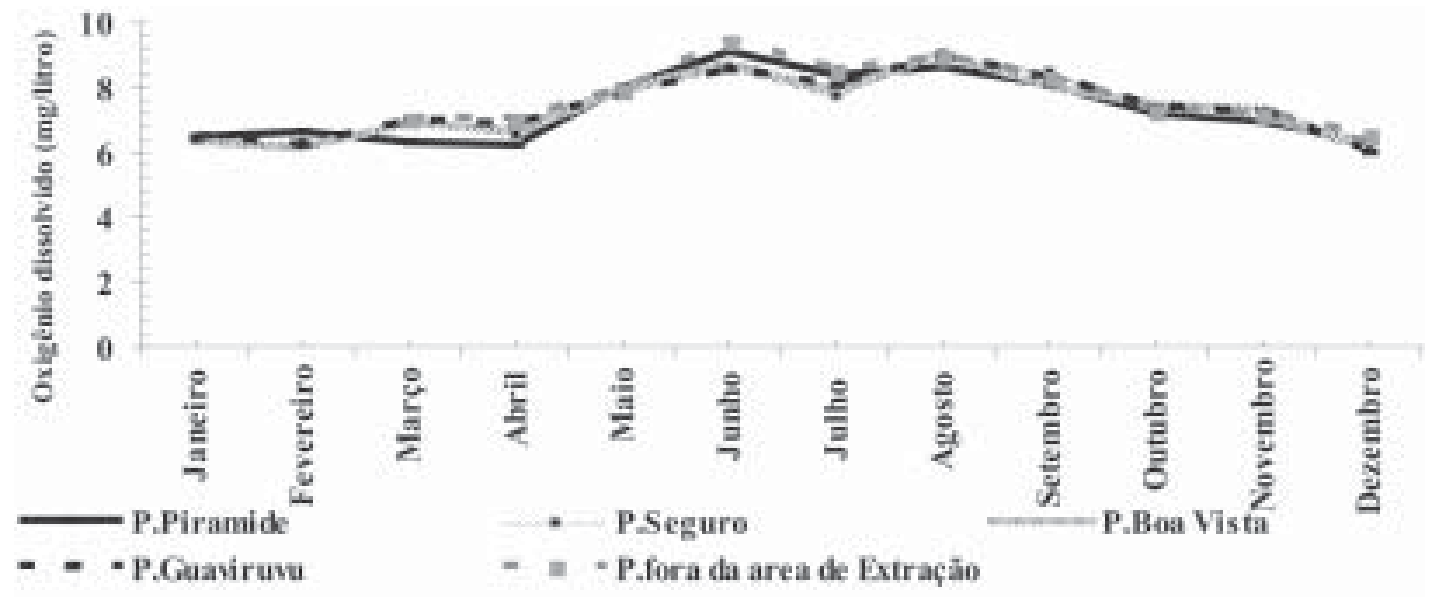

FIGURA 1 - Teor de oxigênio dissolvido ( $\left.\mathrm{mg} \mathrm{O}_{2} \mathrm{D} \mathrm{L}^{-1}\right)$ nos cinco pontos de coleta no Rio Ribeira de Iguape durante 0 ano de 2007

Figure 1 - W ater dissolved ox ygen $\left(\mathrm{mg}_{2} \mathrm{D} \mathrm{L} \mathrm{L}^{-1}\right)$ in five points of sampling in Ribeira de Iguape River, during the year 2007

$\mathrm{O}$ pH é um parâmetro importante no ecossistema aquático, pois é capaz de determinar a dissolução, precipitação, oxidação e redução de várias substâncias (BO URG ; LO CH, 1995; G ILL, 1996; WEINER, 2000). D urante os doze meses de coleta, como pode ser observado na Figura 2, ocorreram pequenas variações de alcalino para neutro e vice-versa. Entretanto, a média dos doze meses, 7,28 $\pm 0,3$ indica que $0 \mathrm{pH}$ da água se manteve dentro dos valores normais para desenvolvimento da vida aquática.

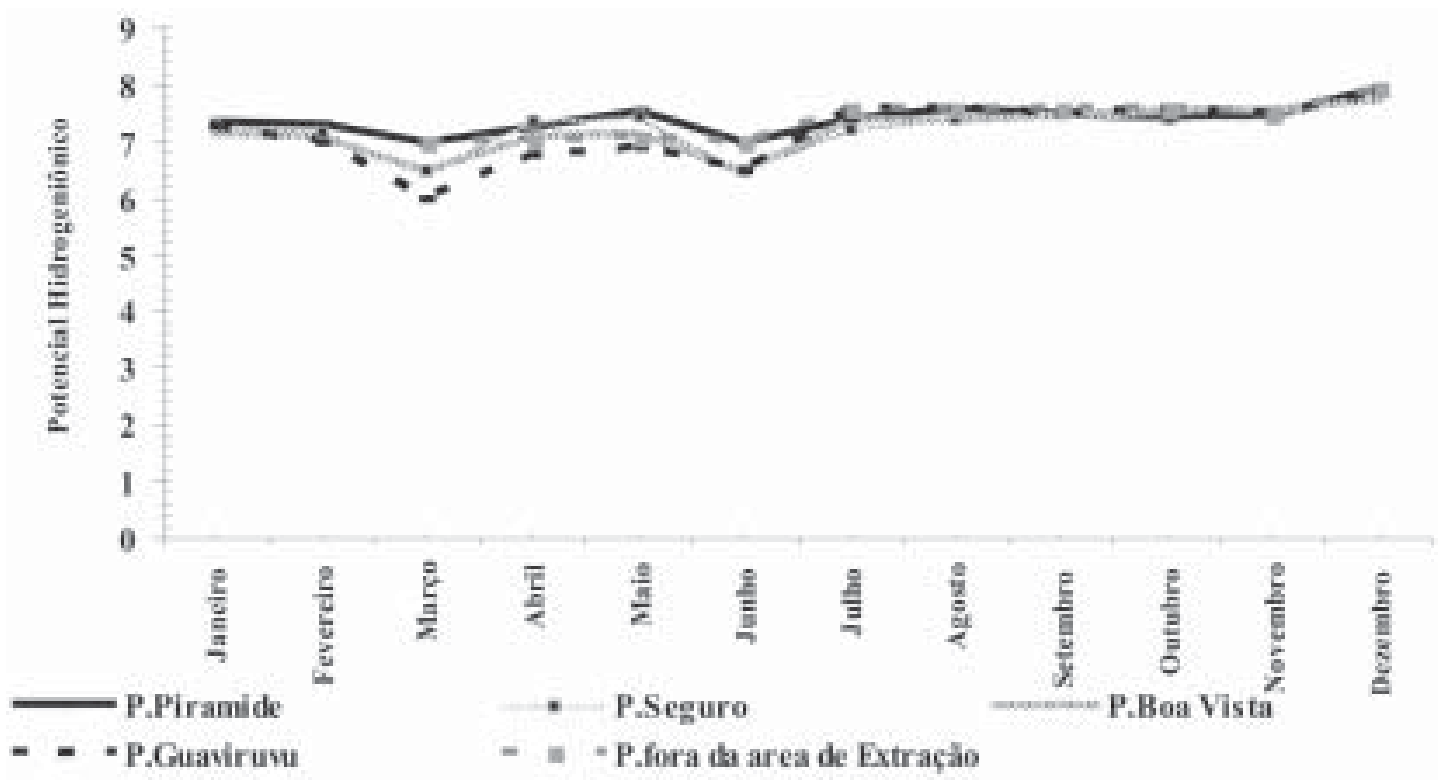

FIGURA 2 - Potencial Hidrogeniônico nos cinco pontos de coleta no Rio Ribeira de Iguape, durante 0 ano de 2007

Figure 2 - pH in five points of sampling in Ribeira de Iguape River, during the year 2007 
A transparência da água oscilou de 20 a $95 \mathrm{~cm}$ durante os doze meses de coleta. D e acordo com o observado na Figura 3, pode-se concluir que as chuvas interferiram diretamente nesse parâmetro, pois nos meses em que se registraram os maiores índices pluviométricos foram detectados os menores índices de transparência e vice-versa.

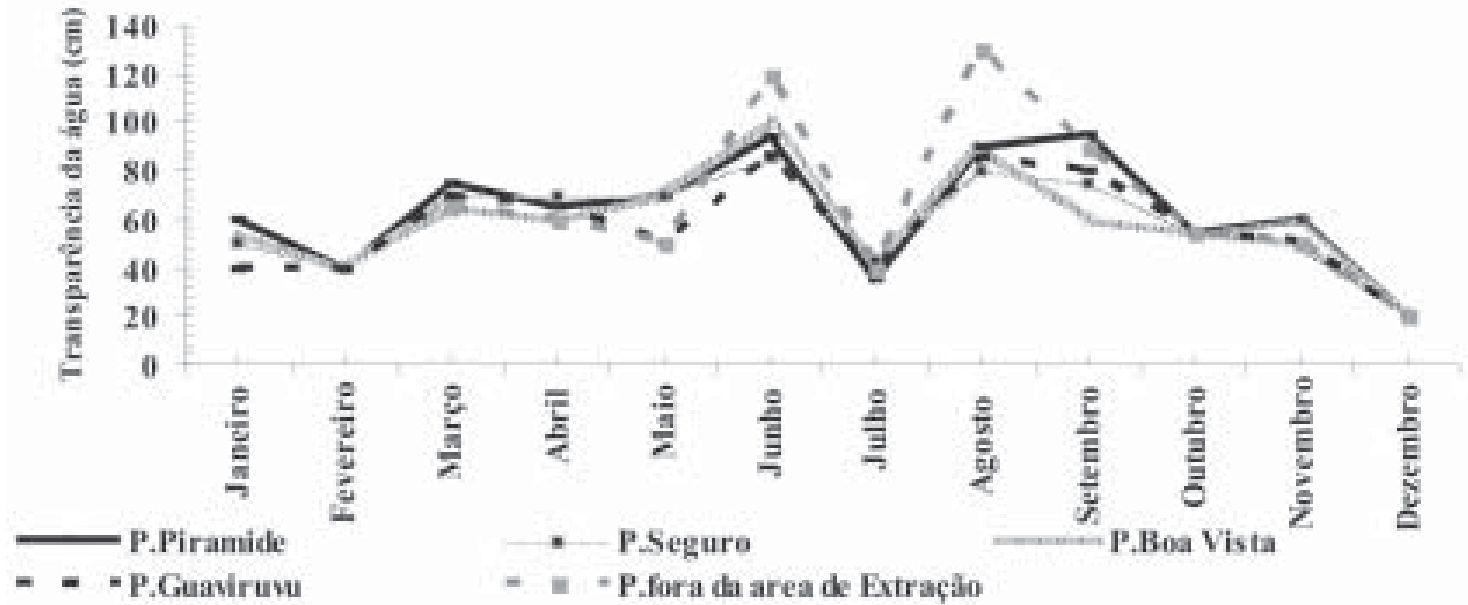

FIG URA 3 - Transparência da água $(\mathrm{cm})$ nos cinco pontos de coleta no Rio Ribeira de Iguape durante 0 ano de 2007

Figure 3 - W ater transparency $(\mathrm{cm})$ in five points of sampling in Ribeira de I guape River, during the year 2007

Esta maior turbidez observada na água é devido à presença de partículas em suspensão, provocando fenômenos de reflexão e dispersão dos raios luminosos que atravessam o meio (ESTEVES, 1988) e é facilmente explicada, pois as chuvas que tocam o solo das margens do Rio Ribeira de Iguape na área estudada $(14 \mathrm{~km})$ não encontram barreiras de contenção, provocando muitas vezes deslizamentos, ocasionando assoreamento do rio e o escurecimento da água. O s efeitos da turbidez na qualidade da água dizem respeito à penetrabilidade da luz, isto é, as águas coloridas ou turvas perdem transparência e isso pode provocar grandes distúrbios ecológicos no meio, por limitar a quantidade de luz indispensável a algumas atividades fisiológicas dos microrganismos, como por exemplo a fotossíntese das algas e outros vegetais submersos (WETZEL, 1975).

D urante esse ano de coleta, o outono e inverno foram mais rigorosos do que nos últimos anos, pois foram registradas nos meses de julho e agosto temperaturas abaixo de $20^{\circ} \mathrm{C}$ (Figura 4). A temperatura é um dos principais limitantes dos vários processos biológicos, desde a velocidade de simples reações químicas até a distribuição ecológica das espécies animais (ESTEVES, 1988). As temperaturas observadas no presente trabalho, para peixes tropicais, representam um estado de "alerta", pois como os peixes são pecilotermos, a temperatura ambiental tem profundo efeito sobre o crescimento, a taxa de alimentação e 0 metabolismo destes animais. 


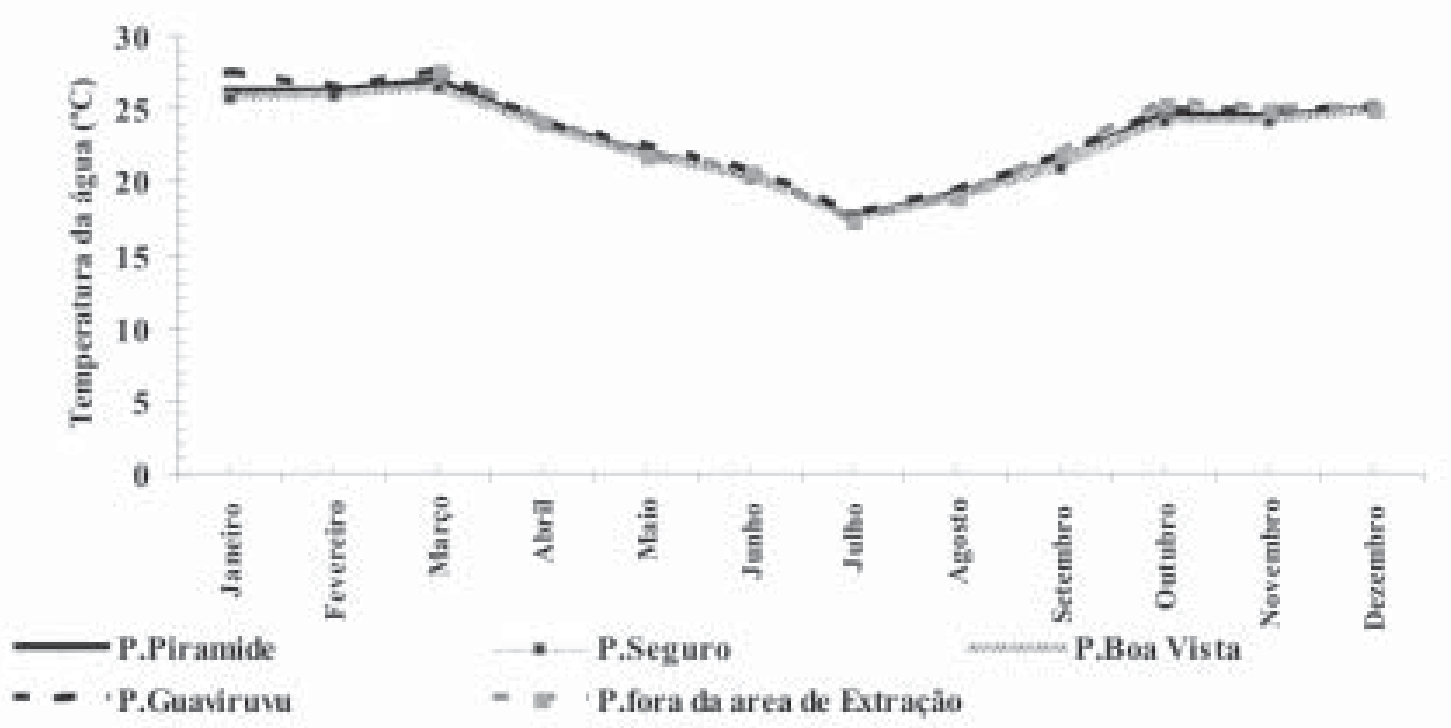

FIG URA 4 - Temperatura da água $\left({ }^{\circ} \mathrm{C}\right)$ nos cinco pontos de coleta no Rio Ribeira de Iguape durante 0 ano de 2007

Figure 4 - W ater temperature $(\stackrel{\circ}{C})$ in five points of sampling in Ribeira de Iguape River, during the year 2007

A concentração de amônia total na água (Figura 5), oscilou de 0,006 a 0,012 mg/ L, valores que não apresentam riscos de toxidez para os organismos do Rio Ribeira de Iguape. A amônia é uma substância liberada pela atividade ou metabolismo dos organismos presentes na água. D esde a degradação da matéria orgânica pelas bactérias até as atividades fisiológicas dos peixes contribuem para o acúmulo de amônia na água. 0 excesso deste pode acarretar toxidez para os organismos, causando mortalidades.

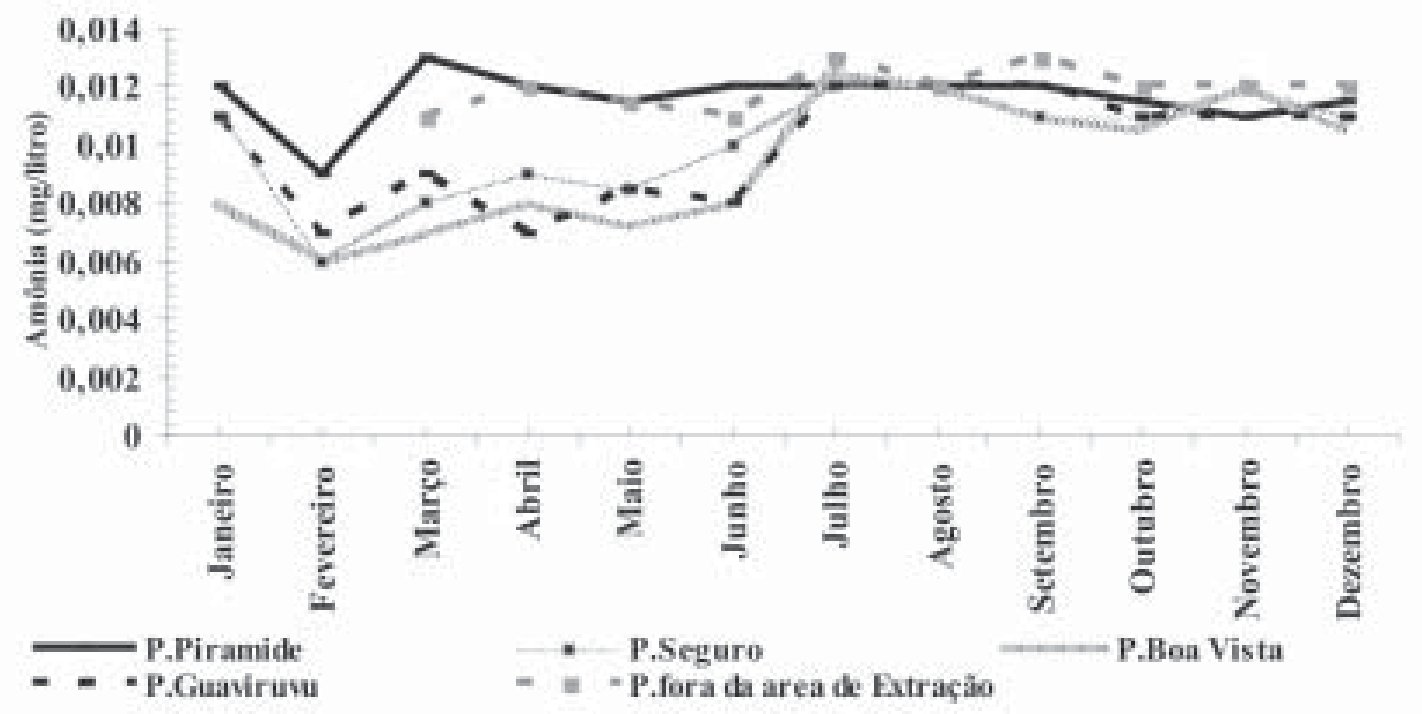

FIG URA 5 - Concentração de Amônia total $\left(\mathrm{mg} / \mathrm{L}^{-1}\right)$ nos cinco pontos de coleta no Rio Ribeira de Iguape durante 0 ano de 2007

Figure 5 - Total ammonia concentration ( $\left.\mathrm{mg} \mathrm{L}^{-1}\right)$ in five points of sampling in Ribeira de Iguape River, during the year 2007 
A condutividade elétrica (Figura 6) representa a quantidade de partículas que estão em suspensão na água, e pode ser utilizada como um parâmetro de avaliação das modificações na composição total das águas. Os valores médios obtidos nos quatro pontos de extração de areia foram $62,7 \pm 4,45 \mathrm{~mm}$ indicando equilíbrio do meio aquático, pois valores acima de $150 \mu \mathrm{m} / \mathrm{L}$ podem indicar índices de poluição.

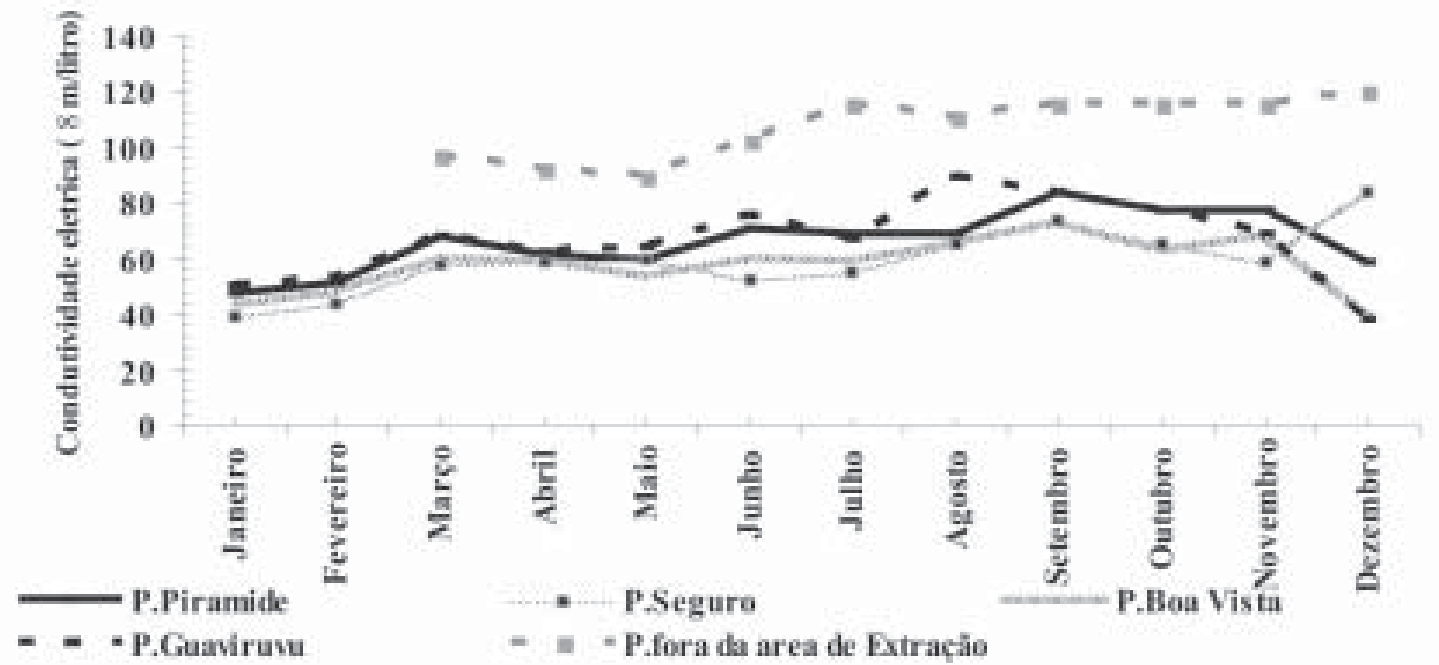

FIGURA 6 - Condutividade Elétrica $\left(\mathrm{mm} / \mathrm{L}^{-1}\right)$ nos cinco pontos de coleta no Rio Ribeira de Iguape durante 0 ano de 2007

Figure 6 - E lectric conductivity $\left(\mathrm{mm} \mathrm{L}^{-1}\right)$ in five points of sampling in Ribeira de Iguape River, during the year 2007

Já o ponto fora da extração de areia (junção do Rio Juquiá com Rio Ribeira de Iguape) apresentou valor médio de condutividade elétrica $(107,63 \pm 22,88 \mathrm{~mm}), 57,6 \%$ superior aos dos pontos extração de areia. Nesse local, devido à junção dos rios, a velocidade da água remexeu o fundo do rio; com isso ocorreu um aumento de partículas em suspensão de matéria orgânica provocando um aumento da condutividade elétrica. Essas alterações podem ser explicadas se for compreendida a localização geográfica de cada rio, pois a hidrologia, geologia e a paisagem concorrem para provocar alterações nas características físicas e químicas da água. O Rio Ribeira de Iguape está inserido em uma região que abrange os maiores pedaços remanescentes da Mata Atlântica e seu curso superior segue um caminho caudaloso entre montanhas, passando por pequenas cidades pacatas, à procura de uma saída para o mar.

Já o Rio Juquiá, que desemboca no Rio Ribeira de Iguape, é fonte de alimento de comunidades ribeirinhas. Ao mesmo tempo sua poluição vem sendo uma constante ameaça, pois praticamente toda a população que vive às margens deposita seu esgoto nele.

A alcalinidade total (Figura 7) refere-se à concentração de bases na água e à capacidade da água em resistir às mudanças do pH (poder tampão). A USEPA (1997) recomenda uma alcalinidade mínima de $20 \mathrm{mg} \mathrm{CaCO}_{3} /$ litro, pois águas que apresentam valor abaixo têm baixo poder tampão. D urante as coletas a variação foi mínima entre os pontos de extração de areia, com valores médios de $68,50 \pm 2,0 \mathrm{mg} \mathrm{CaCO}_{3}$ / litro, sugerindo que nesse trecho estudado o rio está em equilíbrio. Contudo, no ponto fora da área de extração de areia, o valor médio de alcalinidade foi mais elevado durante os doze meses de coleta $(105,71 \pm 14,1 \mathrm{mg} \mathrm{CaCO}$ / litro). A turbulência das águas pode aumentar a taxa de gás carbônico $\left(\mathrm{CO}_{2}\right)$ dissolvido, causando elevação da alcalinidade, principalmente no período das chuvas (G UIMARÃE S-SILVA et al., 2007). 


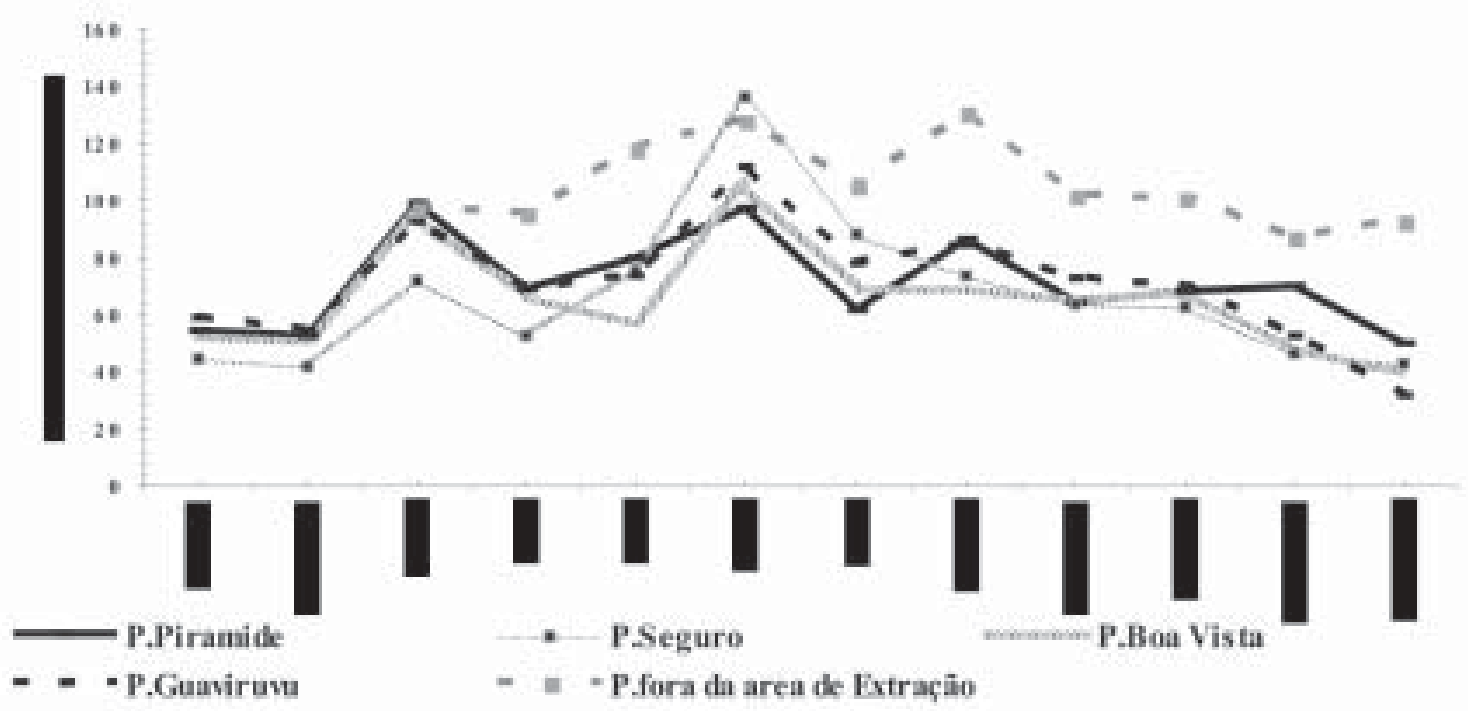

FIGURA 7 - Alcalinidade total da água $\left(\mathrm{mg} / \mathrm{CaCO}_{3} \mathrm{~L}^{-1}\right)$ nos cinco pontos de coleta no Rio Ribeira de Iguape durante 0 ano de 2007

Figure 7 - W ater total alkalinity $\left(\mathrm{mgCaCO}_{3} \mathrm{~L}^{-1}\right)$ in five points of sampling in Ribeira de Iguape River, during the year 2007

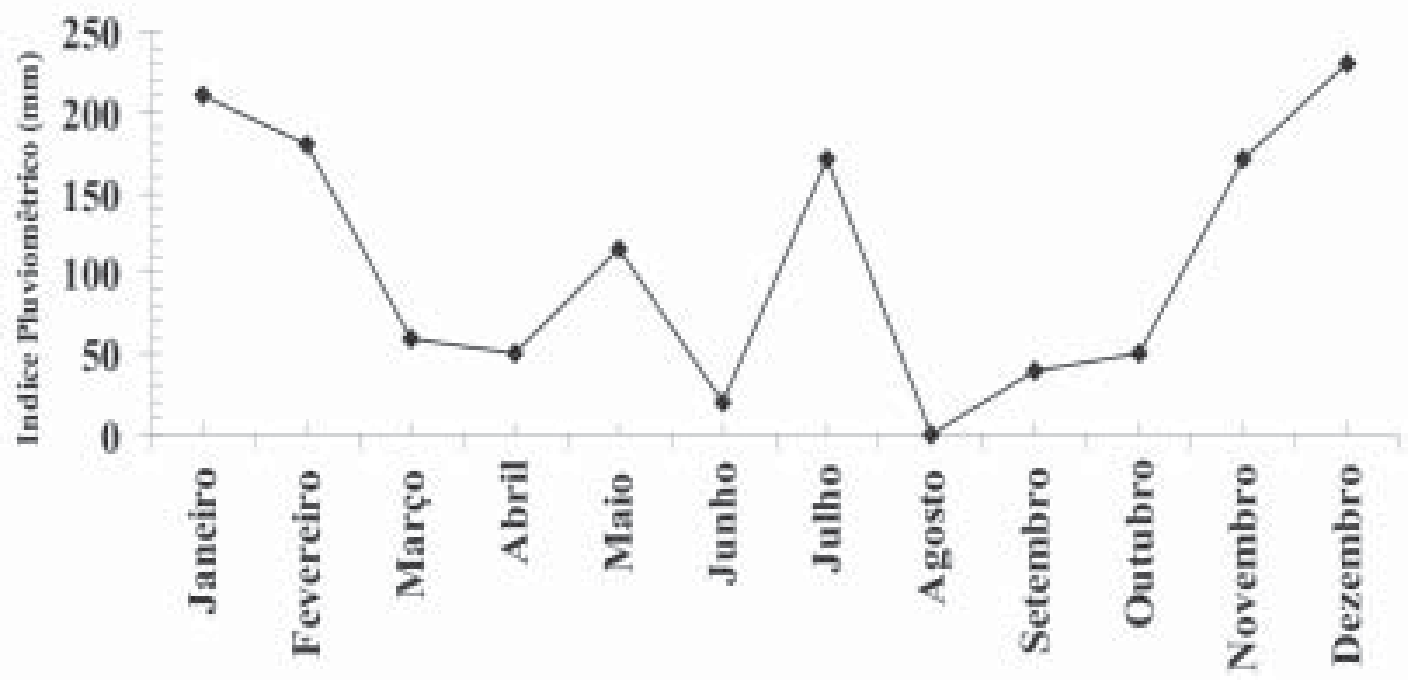

FIG URA 8 - Índice pluviométrico $(\mathrm{mm})$ durante 0 ano de 2007

Figure 8 - Pluviometric level (cm) during the year 2007 


\section{CONCLUSÃO}

D urante os doze meses de coleta, a atividade de extração de areia não causou alterações que comprometessem a qualidade física e química da água na área estudada do Rio Ribeira de Iguape.

\section{AGRADECIMENTOS}

À Associação dos Mineradores de Areia do Vale do Ribeira e Baixada Santista -AMAVALE S pelo apoio financeiro e logístico.

Aos técnicos do Polo Regional do Vale do Ribeira do Setor de Piscicultura, Benedito de Aguiar Martins e Edilberto Rufino de Almeida.

\section{REFERÊNCIAS}

ARANA, L. V. Princípios químicos de qualidade da água em aqüicultura. Florianópolis: Editora da UFSC, 1997.

BARRELLA, W.; BEAUMORD, A. C.; PETRERE Jr., M. Comparación de la comunidade de peces de los Rios Manso (MT) y jacare pepira (SP), Brasil. Acta Biologica Venezuelana, v. 15, n. 2, p. 11-20, 1994.

BARRELLA, W. et al. As relações entre as matas ciliares, os rios e os peixes. Matas ciliares: conservação e recuperação. 2. ed. São Paulo: FAPESP, 2001.

BERKMAN, H. E.; RABENI, C. F. Effect of siltation on stream fish communities. E nvironmental Biology of Fishes, v. 18, n. 4, p. 285-294, 1987.

BO URG, A. C. M.; LO CH, J. P. G. Mobilization of heavy metals as affected by $\mathrm{pH}$ and redox conditions. In: SALO MO NS, W.; STIG LIANI, W. M. (Ed.). Biogeodynamics of pollutants in soils and sediments: risk assessment of delayed and non-linear responses Germany: Springer, 1995. p. 87-102.

BRANCO, S. M.; RO CHA, A. A. Poluição, proteção e usos múltiplos das represas. São Paulo: CETESB/ Edguard Blucher, 1977.

DEPARTAMENTO NACIONAL DE PRODUÇÃO MINERAL - DNPM. Extração de areia. Disponível em: <http:www.dnpm.gov.br>. Acesso em: 30 mar. 2008.

ESTEVES, F. A. Fundamentos de limnologia. Rio de Janeiro: Interciência/ FINEP, 1988.

GILL, R. Chemical fundamentals of geology. 2nd ed. London: Chapman \& Hall, 1996.

GOLTERMAN, H. L.; CLYMO, R. S.; OHNSTAD, M. A. M. Methods for physical and chemical analysis of freshwater. London: Blackwell Sci. Pub, 1978.

GUIMARÃE S-SILVA, A. K. et al. Q ualidade das águas na região dos garimpos de topázio imperial na sub-bacia do rio da Ponte, O uro Preto-MG. Revista Escola de Minas, v. 60, n. 4, p. 603-611, 2007.

INTERNATIONAL UNION FOR CONSERVATION OF NATURE - IUCN. Estratégia mundial para a conservação dos recursos vivos para um desenvolvimento sustentado. São Paulo: CESP, 1984.

KOROLEFF, F. D etermination of nutrients. In: GRASSHOFF, K. (Ed.). Methods of seawater Analysis. New York: Verlag Chemie Weinhein, 1976. p. 117-181. 
LELLES, L. C. et al. Perfil ambiental qualitativo da extração de areia em cursos d'água. Revista Árvore, v. 29, n. 3, p. 1-7, 2005.

UNITED STATES ENVIRONMENTAL PROTECTION AGENCY - USEPA. Monitoring water quality. Volunteer stream monitoring: a methods manual. Manual Organization, EPA 841 B 97 003. p. 4503, 1997.

WEINE R, E. R. Applications of environmental chemistry: a practical guide for environmental professionals. Florida: CRC Press, Lewis Publishers, 2000.

WETZEL, R. G. Limnologia. Philadelphia: W. B. Saunders Company, 1975.

Recebido: $17 / 04 / 2008$

Received: 04/ 17/ 2008

Aprovado: 10/ 09/ 2008

A pproved: 09/10/2008 